\title{
TU/e EmonONEN

\section{A review of recent advances in decompositional preference and choice models}

\section{Citation for published version (APA):}

Louviere, J. J., \& Timmermans, H. J. P. (1990). A review of recent advances in decompositional preference and choice models. Tijdschrift voor Economische en Sociale Geografie = Journal of Economic and Social

Geography, 81(3), 214-224. https://doi.org/10.1111/j.1467-9663.1990.tb00772.x

DOI:

10.1111/j.1467-9663.1990.tb00772.x

Document status and date:

Published: 01/01/1990

\section{Document Version:}

Publisher's PDF, also known as Version of Record (includes final page, issue and volume numbers)

\section{Please check the document version of this publication:}

- A submitted manuscript is the version of the article upon submission and before peer-review. There can be important differences between the submitted version and the official published version of record. People interested in the research are advised to contact the author for the final version of the publication, or visit the $\mathrm{DOI}$ to the publisher's website.

- The final author version and the galley proof are versions of the publication after peer review.

- The final published version features the final layout of the paper including the volume, issue and page numbers.

Link to publication

\section{General rights}

Copyright and moral rights for the publications made accessible in the public portal are retained by the authors and/or other copyright owners and it is a condition of accessing publications that users recognise and abide by the legal requirements associated with these rights.

- Users may download and print one copy of any publication from the public portal for the purpose of private study or research.

- You may not further distribute the material or use it for any profit-making activity or commercial gain

- You may freely distribute the URL identifying the publication in the public portal.

If the publication is distributed under the terms of Article 25fa of the Dutch Copyright Act, indicated by the "Taverne" license above, please follow below link for the End User Agreement:

www.tue.nl/taverne

Take down policy

If you believe that this document breaches copyright please contact us at:

openaccess@tue.nl

providing details and we will investigate your claim. 


\title{
A REVIEW OF RECENT ADVANCES IN DECOMPOSITIONAL PREFERENCE AND CHOICE MODELS
}

\author{
by \\ JORDAN LOUVIERE* \& HARRY TIMMERMANS** \\ Edmonton, Canada \& Eindhoven, The Netherlands
}

\section{Introduction}

To date there have been many applications of decompositional multiattribute preference and choice models to study the behaviour of individuals in geography, marketing, town planning and transportation. These models have played and continue to play an important role in describing the process of preference formation and choice by individuals faced with making choices among two or more nondominated alternatives. Decompositional models have the advantage of being based on experimental measurements, thereby enabling one to control for possible disturbances not associated with the variables of research interest, and to construct choice alternatives not presently in the domain of individuals' market experiences. A detailed exposition of decompositional multiattribute decision models is provided by Timmermans (1984) and Louviere (1988b).

Despite these advantages, decompositional decision models nevertheless have a number of unresolved problems and limitations, such as the following:

(1) An integrated theoretical framework linking preferences or behavioural intentions to choice behaviour is lacking.

(2) The form or parameters of utility or deci-

* Department of Marketing and Economic Analysis, University of Alberta, 3-23 Faculty of Business Building, Edmonton, T6G 2R6, Canada.

** Department of Architecture and Urban Planning, Eindhoven University of Technology, P.O. Box 513, 5600 MB Eindhoven, The Netherlands.

Received June 1989; revised September 1989. sion functions may vary with differences in choice set composition and therefore may not be context-independent.

(3) Task demands for individual respondents become more and more onerous as the number of attributes and/or the number of levels of attributes increase.

(4) Some combinations of attribute levels produced by experimental designs can result in the creation of unrealistic, hypothetical choice alternatives not encountered in real markets.

(5) It is difficult to predict the expected market shares of new choice alternatives in situations in which it is reasonable to expect competitive responses from existing alternatives.

The purpose of this article is to review a number of recent developments that can wholly or partially solve some of the aforementioned problems and limitations. To accomplish this purpose, the article is organized as follows: we first summarize the state-of-theart in decompositional multiattribute decision models and conjoint choice simulation techniques; and then we describe several recent advances in solving the previously mentioned problems and limitations.

\section{Conjoint choice simulation techniques}

A multiattribute choice alternative is defined as a choice option which can be chosen by a decision maker, including the choice of 'not choosing'. Each such choice option can be described by its position on one or more attributes relevant to the decision maker. For example, consumers in larger urban centres 
often can choose among several shopping centres for particular needs. Let us therefore describe the $Z$-th shopping centre as an ordered $m$-tuple consisting of $m$ separate pieces of information describing the position of the shopping centre on $m$ attributes relevant to choice. That is,

$Z=\left(x_{1}, x_{2}, \ldots, x_{j}, \ldots, x_{m}\right)$,

where $x_{j}$ is the position or level of $Z$ on the $j$ th attribute.

Decompositional decision models are based on the assumption that an individual's choices are the result of a several-stage process: (1) subjective evaluation of the positions of each alternative on each attribute; (2) integration of the separate subjective evaluations of each attribute position into an overall evaluation of each alternative; (3) development of a strategy for translating the overall evaluations of competing alternatives into a single choice (e.g., 'Choose the most highly evaluated choice alternative within the budget constraint.'). Conjoint analysis techniques provide a rigorous basis for studying and modeling stages one and two of the process just described. In particular, conjoint analysis techniques allow one to study the information integration process, and to decompose an individual's overall evaluations into the separate subjective evaluations of each attribute position. Described as the 'conjoint measurement problem' (Luce \& Tukey 1964; Krantz 1964), all conjoint analysis techniques have in common procedures for simultaneously measuring (or decomposing the overall evaluation into) the joint effects of two or more attributes on the individual's overall evaluations of a statistically designed set of multiattribute alternatives.

Applied conjoint analysis work typically involves the following. (a) A model that describes how the separate attribute positions are integrated is assumed (e.g., an additive integration process). (b) An experimental design is used to generate a set of hypothetical choice alternatives by varying the positions of the attributes in a controlled manner. This, of course, requires one to (i) identify the attributes which are relevant to individuals' decisions, (ii) define relevant levels or positions for these attributes in the study domain of interest, and (iii) combine the attribute levels into hypothetical choice alternatives by means of an appropriately selected experimental design (choice of design is largely dictated by one's functional form assumptions). (c) An evaluation task is developed in which individuals rank-order, rate or otherwise express their evaluations of or preferences for the designed multiattribute alternatives in a quantitative manner. (d) The individuals' overall evaluations of the designed alternatives are decomposed into a set of part-evaluations or part-preferences (part-worth utilities) associated with every level or position of each attribute.

The ability of the estimated part-worth measures to recover an individual's observed numerical evaluation responses is usually assessed by a goodness-of-fit measure like Rsquare or 'stress'. Stress can be thought of as one minus $\mathrm{R}^{2}$, and hence, is like the inverse of the usual regression measure of fit. The bestfitting conjoint model for a given decision task (for a particular individual) is identified by comparing these goodness-of-fit measures for alternative models. Stress measures are normally used with parameter estimation techniques applied to rank-order evaluation data, while R-square and OLS regression analysis is more typical of category ratings evaluation data.

A variety of paradigms exists to study individuals' decision making processes, some of which are rank-order Conjoint Measurement (Krantz \& Tversky 1971), metric (rating or choice data) Functional Measurement (Anderson 1981, 1982), and metric (normally rating data) Judgment Policy Capturing (Hammond et al. 1977). 'Conjoint Analysis' (Green \& Srinivasan 1978) refers to the use of one or more decompositional modeling procedures to estimate part-worth values from individuals' overall evaluations of designed multiattribute alternatives.

Once part-worth measures have been estimated, one must postulate a choice rule in order to predict the choices that an individual is likely to make given the conjoint results. A simple, commonly used choice postulate is that an individual will choose that alternative that is observed or predicted to have the highest overall evaluation (or utility). Alternatively, different probabilistic rules can be postulated (e.g., Timmermans \& Van der Heijden 1984). The choice behaviour of individuals can be simulated by (i) defining real-world alternatives in terms of their positions or levels on each decision attribute varied in the evaluation task, (ii) calculating each individual's overall utility score for each alternative on the 
basis of the estimated part-worth function, and (iii) using a postulated choice rule to map an individual's estimated overall evaluations (utilities) into choices.

Conjoint analysis and similar decision analysis techniques (e.g., multiattribute utility or decision theory-based procedures) have been successfully applied to a wide variety of problems in geography, urban planning, marketing and transportation for the past decade. For example, applications have been reported in commercial geography (Prosperi \& Schuler 1976; Schuler \& Prosperi 1978; Schuler 1979; Timmermans 1980, 1982; Moore 1988), transportation geography and planning (Norman \& Louviere 1974; Louviere \& Norman 1977; Bates 1988; Dinwoodie 1989), migration and residential decision making (Lieber 1978, 1979; Louviere 1979, 1988a; Veldhuisen \& Timmermans 1984; Phipps \& Clark 1988), recreational geography and planning (Lieber \& Fesenmaier 1984; Curry et al. 1983), route choice behaviour (Bradley \& Bovy 1984) and locational choice (Timmermans 1986) to name only a few. Most of these studies were concerned with uncovering individuals' preferences for various alternatives, and involved fairly simple experimental designs and a limited set of choice attributes. Only a few studies attempted to determine a functional relationship between estimated preferences for alternatives and overt choice behaviour.

\section{The problem of linking preferences, evalua-} tions or utilities to choices

Most current applications of decompositional multiattribute decision models try to predict real world choice behaviour by using the deterministic choice rule that 'choice equals highest predicted overall evaluation or utility'. This approach is theoretically inadequate because one uses a deterministic rule to predict a probabilistic phenomenon. Furthermore, the statistical properties of the part-worth and overall utility measures derived from rankings of hypothetical choice alternatives are unknown and may be inappropriate for predicting choice behaviour.

However, if one is willing to make assumptions regarding the distribution of the error terms of the conjoint derived utility measures, one can avoid some of these problems (see e.g. Timmermans et al. 1984). Distributional assumptions, of course, allow for probabilistic choice processes but do not allow one to test the validity of the assumptions except with re- spect to some external criterion like real choice behaviour. Unfortunately, at the present time tractable choice process models typically require a fairly rigorous and restrictive set of assumptions. For example, assuming that the errors are distributed as Type I Extreme Value random variables results in the Multinomial Logit (MNL) choice model; however, this model makes very strong predictions about the behaviour of choice probabilities, and these predictions are seldom satisfied in real choice data.

Louviere \& Woodworth (1983) have suggested an approach to studying choice behaviour that enables one to study both the evaluation and choice processes simultaneously. As with more traditional conjoint ranking or rating procedures, one first identifies a set of decision attributes together with appropriate positions or levels for those attributes. Multiattribute choice alternatives are generated by means of fractional factorial experimental designs in which each attribute is treated as a factor with varying numbers of levels. If the number of alternatives among which individuals will choose is constant (say $N$ ), and each alternative has $M$ attributes with $L$ levels, one can construct choice sets that satisfy the MNL (or Luce 1959,1977 ) choice model by designing an $L^{M^{*} N}$ main effects, orthogonal, fractional factorial experimental design to create joint combinations of attribute levels. The number of total choice sets is dictated by the number of levels assigned to the various attributes of each alternative.

One can easily generate sets of choice sets that are consistent statistically with MNL models by using standard fractional factorial design techniques to create the choice sets. Choice sets created in this way have a fixed number of alternatives, but the positions of these alternatives on the decision attributes vary from choice set to choice set. It is also convenient to add a constant choice alternative to each choice set to set the origin of the evaluation or utility scale. For example, a logical constant alternative often is to choose 'none' of the other alternatives. Other constant or 'base' alternatives that might make sense are one or more constant alternatives such as existing shopping centres, destinations, etc.

In contrast to the rating or ranking tasks of traditional conjoint analysis approaches to studying individual decision making, the approach involves true 'choice' tasks in which in- 
dividuals select one and only one alternative in each of several experimentally designed choice sets. For example, individuals might be asked to indicate which one shopping centre in a set of such centres is the one that they would be likely to patronize the most frequently for a particular product class or set of product classes. Alternatively, individuals can also be asked to estimate the proportion of their total patronage that they would be likely to allocate to each centre; or, in general to allocate some fixed set of resources (e.g., dollars, points, trips, etc.) to the available choices.

If the MNL choice model is approximately correct, a sufficient condition for estimating the part-worth values for the alternatives is that the independence of alternatives across choice sets be preserved. In practice, an orthogonal, fractional factorial, main effects design for varying the levels of the decision attributes will satisfy this condition. A major advantage of this design approach is that one can test for satisfaction of various MNL model properties, such as IIA (Independence from Irrelevant Alternatives) by including the crosseffects of an alternative on another alternative in the utility arguments. This specification allows one to generalize the MNL model to account for violations of the IIA property due to nesting of or similarities among alternatives.

One can also create designs that satisfy the sufficient conditions of the MNL model, but which do not permit rigorous tests of properties like IIA. Thus, if one has reason to expect that the MNL model will provide a reasonable approximation to choice data, one can construct choice designs by first using separate fractional factorial designs to generate attribute combinations for each alternative. The separate fractional designs for each alternative may be randomly assigned without replacement to each choice set. Of course, the separate designs for each aiternative must either have the same number of treatments or the number of treatments in each separate design must be a common integer multiple. For example, if each of $M$ alternatives has $N$ total treatments, one can randomly assign the $N$ treatments into $M$-tuples without replacement to create choice sets of size $M$. However, if one alternative has nine treatments, a second has 18 and a third has 27 , one must find a common multiple, which in this example is 54. In this case, one would randomly assign the nine treatments allowing six replacements, the 18 allowing 3 replacements and the 27 allowing 2 replacements.

An example of the use of experimental designs with fixed numbers of alternatives to create choice experiments is provided by Louviere \& Hensher (1983). They developed a 'fixed alternatives' choice experiment to study choice of bus vs. auto vs. 'other' modes for the journey-to-work. Three two-level attributes were varied to describe both bus and auto modes: (a) fare, travel time and walking distance to bus stops for bus, and (b) gasoline cost per gallon, travel time and parking costs per hour for auto. Each attribute was treated as a factor used to construct 16 different choice sets based on a 1/4 fractional factorial design of a $2^{6}$ complete factorial (each of the two modes had three attributes at two levels).

Each choice set therefore consisted of separate descriptions of the attribute positions of bus and auto on their respective three attributes. 'Any other mode' was used as a third, or constant base alternative as previously described. Respondents in the study simply indicated which of the three modes they would be most likely to choose in each of the 16 choice sets. The discrete choices of the respondents were aggregated to absolute frequencies of choice, and the parameters of a MNL choice model were estimated from these data by means of weighted least squares regression as explained in the next section on estimation possibilities. Empirical results suggested that the respondents (college students) preferred buses to other modes (all else equal), but were particularly sensitive to changes in bus attributes.

Depending upon the statistical properties of the choice experiment one designs, one can therefore estimate various parameters that represent the marginal or joint effects of each attribute of each alternative on the choice probabilities. The more cross-effect terms that can be independently estimated, the more violations of MNL model properties one can test; and the more general the utility specification that can be estimated. Thus, assuming that some subset of the Universal Logit Model can be estimated from the choice data derived from a choice experiment, one can estimate the parameters of various MNL models directly from the choice data by means of maximum likelihood estimation or one of several other estimation methods. Because methods other than maximum likelihood are less well-known for MNL models, we outline three other esti- 
mation approaches that one might consider.

MNL model estimation possibilities other than maximum likelihood - Theil (1969) discusses a method for estimating linear logit models from multidimensional contingency table data. Because the experimental designs previously described produce incomplete contingency tables, Theil's approach can be used to estimate the parameters of appropriately specified MNL models. This approach involves an analysis of the natural logarithms of the conditional logits for the choice frequencies, or the log odds of choosing one alternative (say $i$ ) over a second constant or base alternative (say $j$ ). If $F_{i}$ and $F_{j}$ are the observed frequencies of choice for the two alternatives $i$ and $j$, the conditional logits are defined as

$\mathrm{L}_{i \mid j}=\operatorname{Ln}\left[F_{i} / \mathrm{F}_{j}\right]$.

One can express this log odds ratio as a linearin-the-parameters-and-attributes function of differences in attribute levels. The observed absolute choice frequencies are used as estimates of the underlying choice probabilities, and because the original probabilities are not independent, generalized least squares regression is used to estimate the parameters. The relevant estimation expression is:

$\boldsymbol{\beta}=\left(\mathbf{X}^{\prime} \mathbf{V}^{-1} \mathbf{X}\right)^{-1} \mathbf{X}^{\prime} \mathbf{V}^{-1} \mathbf{L}$

where,

$\beta$ is the vector of parameters to be estimated;

$\mathbf{X}$ is the design matrix;

$\mathbf{V}$ is the asymptotic variance-covariance matrix of the error terms;

$\mathbf{L}$ is a vector of conditional logits.

The variance-covariance matrix has the following form:

$$
\mathrm{V}^{-1}=\left[\begin{array}{cccc}
\mathrm{p}_{1}\left(1-\mathrm{p}_{1}\right) & -\mathrm{p}_{1} \mathrm{p}_{2} & \ldots & -\mathrm{p}_{1} \mathrm{p}_{\mathrm{I}} \\
-\mathrm{p}_{1} \mathrm{p}_{2} & \mathrm{p}_{2}\left(1-\mathrm{p}_{2}\right) & \ldots & -\mathrm{p}_{2} \mathrm{p}_{\mathrm{I}_{\mathrm{I}}} \\
\cdot & \cdot & & \cdot \\
\cdot & \cdot & & \vdots \\
-\mathrm{p}_{1} \mathrm{p}_{\mathrm{I}} & -\mathrm{p}_{2} \mathrm{p}_{\mathrm{I}} & \ldots & \mathrm{p}_{\mathrm{I}}\left(1-\mathrm{p}_{\mathrm{I}}\right)
\end{array}\right]
$$

A second estimation approach is due to Nakanishi \& Cooper (1974). Originally developed for the Multiplicative Competitive Interaction model, the idea underlying this approach can be applied to estimating the parameters of MNL models. Consider an MNL model of the following form:

$$
p_{i}=\frac{\underset{k}{K}\left(\sum \beta_{k} X_{i k}\right)}{\sum_{j=1}^{J \exp \left(\sum_{k=1}^{K} \beta_{k} X_{j k}\right)}}
$$

where,

$p_{i}$ is the probability that choice alternative $i$ will be chosen;

$X_{i k}$ denotes the $k$ th attribute of the $i$ th choice alternative;

$\beta_{k}$ is a parameter associated with the $k$ th attribute;

$K$ is the total number of attributes, and $J$ is the total number of choice alternatives.

In this approach the above expression can be linearized as follows:

$\ln \left[p_{i}\right]=\underset{k}{\sum} \beta_{k} X_{i k}-\underset{j}{\left.\exp \left(\sum \beta_{k} X_{j k}\right)\right]}$

Summing over $i$ and dividing by $I$ gives:

$\left.\frac{1}{I i} \sum \ln \left[p_{i}\right]=\sum_{k}^{\Sigma} \beta_{k} \frac{1}{I i} \sum_{i} X_{i k}-\ln \underset{j}{[\Sigma} \exp \left(\sum \beta_{k} X_{j k}\right)\right]$

Now define:

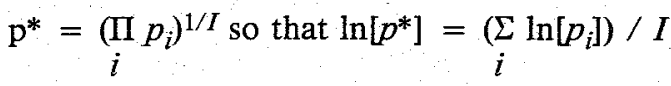

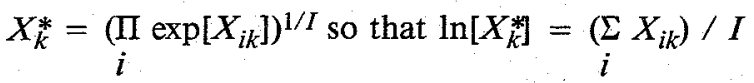

Then, the above equation becomes:

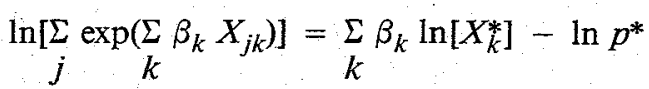

Substitution and rearranging then gives:

$\ln \left[p_{i} / p^{*}\right]=\underset{k}{\Sigma} \beta_{k}\left(X_{i k}-\frac{1}{I} \sum_{j} X_{j k}\right)$

The parameters of the latter expression can be estimated by OLS regression under the assumption that the sampling errors are negligible and the specification errors are uncorrelated. If one cannot assume satisfaction of these assumptions, then GLS regression procedures should be used.

A third approach is due to Louviere, Woodworth \& Anderson (1981). They use weighted multiple linear (or GLS) regression to estimate the parameters of MNL models from the absolute frequencies of choice of each alternative 
in each choice set. The dependent variable is the natural logarithm of the absolute choice frequency, which is an estimate of the underlying probability. Independent variables are the attribute vectors, alternative-specific dummies and dummies to represent the denominator of the MNL model in each choice set. $\mathrm{Al}$ ternatively, the choice set denominator dummies can be treated as a categorical variable with $C$ total levels ( $C$ is the number of choice sets) analogous to analysis of variance treatment of such variables. Woodworth \& Louviere (1985) demonstrate that this approach produces the maximum likelihood estimates by iteratively updating the weight and parameter vectors. This latter approach is known as iteratively reweighted least squares estimation. The elements of the weight vector for the one-step approach are the observed absolute choice frequencies for each alternative. In the iterative procedure, the weighting elements are the predicted frequencies based on the previous iteration's updated parameter estimates.

The validity of the MNL model can be tested statistically with these estimation procedures if one's experimental design allows the estimation of cross-alternative (interaction) effects. For example, the IIA property of the MNL choice model requires that the utility of a particular alternative cannot be influenced by the presence or absence of the attribute levels of any other alternative in the same choice set. Satisfaction of this condition can be tested by estimating the (interaction) effects of each alternative on the other alternatives. If the MNL model is approximately correct, all of the two-way interactions between the choice alternatives should be non-significant.

\section{Varying choice set composition}

Our discussion thusfar has been concerned with choice problems in which every choice alternative is present in every choice set ('fixed alternatives'). However, it may be the case that the composition of choice sets affects individuals' choices; but this effect cannot be studied with 'fixed alternative' designs, except insofar as such designs accommodate crosseffects between the alternatives. In general, however, individuals face choice sets of varying sizes and composition, and one would like to be able to study changes in choice behaviour in such situations with controlled choice experiments. Traditional conjoint analysis approaches that rely on individuals' nu- merical evaluations of a single fixed set of multiattribute alternatives cannot accommodate the effects of varying choice set size and composition on choice behaviour because individuals' responses to such contextual changes are not explicitly observed.

Even studies which identify different choice sets (so-called 'evoked' sets) for each individual a priori cannot accommodate variations in choice set sizes and composition because responses to such variations are not observed. Given the importance of understanding violations of simple assumptions about choice behaviour, such as the IIA consequences of the simple MNL choice model, the ability to directly analyze such effects is significant.

The 'fixed alternatives' design problem previously discussed can be extended to address this problem. As in previous approaches, one first determines a set of decision attributes and levels of research interest. The levels or positions of these attributes are then combined by means of a controlled experimental design to produce hypothetical multiattribute choice alternatives. This so-called 'alternative generating' design is usually identical in spirit to a traditional conjoint analysis design.

Each of the multiattribute choice alternatives produced from the 'alternative generating' design then are treated as separate twolevel (present/absent) factors in a second, or 'choice set generating' design. The 'choice set generating' design is usually some fraction of a $2^{N}$ ( $N$ is the number of total designed multiattribute alternatives created by the 'alternative generating' design) factorial design. 'Choice set generating' designs are used to place alternatives into choice sets in such a way that the necessary and sufficient statistical conditions for estimating and testing the MNL choice model are satisfied. A $2^{N}$ factorial is an appropriate design vehicle for this problem because all possible choice sets consisting of different combinations of $N$ aiternatives is given by that factorial. Thus, the MNL design problem is equivalent to selecting orthogonal fractions from the $2^{N}$ factorial in such a way that the effects of interest can be estimated independently.

Fractions of $2^{N}$ designs produce choice sets that vary in size and composition. Individuals are asked to choose one and only one alternative from each of the designed choice sets (or subsets of choice sets). As before, one can add a constant, base alternative to each choice set, such as the choice of 'none' of the alternatives. 
Alternatively, individuals can be asked to allocate some fixed set of resources such as trips, visits, dollars, points, etc. to each alternative in each choice set. As $N$ grows large, $2^{N}$ designs become cumbersome, producing relatively large choice sets and complicated, onerous and time-consuming tasks for respondents. In these cases, one can use other types of designs such as randomized incomplete block designs, balanced incomplete block designs and partially balanced incomplete block designs. Generalized MNL models or any subsets thereof can be estimated from appropriately specified designs by means of maximum likelihood or any of the other parameter estimation methods previously described.

\section{The information overload problem}

Many individual decision problems are complex and involve many potentially influential attributes. Such problems are difficult to handle using any of the existing decompositional conjoint approaches. For example, a full factorial design for nine three-level attributes produces $3^{9}$ (or 19,683 ) total combinations, or different multiattribute alternatives. Of course, this is far too many to be evaluated by respondents, even if the design were to be blocked into 100 different blocks. A fractional factorial design that would permit one to estimate the two-way interactions among the attributes, assuming negligible higher-order interactions, would require at least 162 combinations, also too many to administer to individual subjects outside of psychology laboratories. Thus, in applied problems, researchers have typically adopted one of the following strategies to reduce the complexity of the design and resulting task:

(1) Use a priori or other ad hoc assumptions to reduce the number of decision attributes by deciding to use only a few.

(2) Use an analytic procedure applied to some a priori available external data source to reduce the number of attributes by applying a statistical data reduction criterion.

(3) Extend the two-attribute-at-a-time tradeoff approach to a fairly large number of attributes presented in pairs using balanced incomplete block or other connected designs.

None of these strategies is wholly satisfactory because they are either ad hoc, fail to reduce the complexity by very much, or introduce possible artifacts into the task that do not exist in the real world (e.g., considering only two attributes at a time). Planners or managers, however, usually need to be able to assess the consequences of manipulating a relatively large number of separate attributes simultaneously, and it would be useful to have a method based on a theory of how individuals made decisions in such situations as a basis for task construction. Two approaches have recently been suggested to deal with this problem. The first, suggested by Green and his associates (1981) is based on an ad hoc method of combining attitude scales and controlled experiments, and will not be pursued in this article. The second, suggested by Louviere (1984a) is called Hierarchical Information Integration, and involves a theory about the way in which individuals simplify decisions in order to take into account a large number of attributes.

The Hierarchical Information Integration approach is based on the hypothesis that for many decision problems it makes sense for individuals to group the possible influential decision attributes into sets. Each such set defines a separate, higher-order decision construct, and individuals use rules to integrate attributes into decision contents and decision constructs into overall evaluations and choices. The idea behind Hierarchical Information Integration is to structure a decision task in such a way to allow one to study and analyze each of these integration processes separately.

Hierarchically structured conjoint tasks involve the following steps:

(1) Attributes are clustered into a fixed number of sets based on logic, empirical evidence or theory. Each set represents a different, high-order decision construct. For example, 'convenience' of a shopping centre is a higher-order construct that may be defined by attributes like number of parking spaces, shopping hours, driving distance or time, etc.

(2) Separate experimental designs are constructed for each of the sets identified in Step 1 to produce multiattribute alternatives that define various levels, positions or degrees of the decision construct represented by each set. Individuals are asked to evaluate each combination of attribute levels or positions in a particular construct set on some category rating scale that defines 'how much' of the construct is represented or defined by each combination of attributes. 
(3) The response data for each construct set obtained in Step 2 are separately analyzed to develop statistical models that describe how the different attributes associated with each construct combine to define or represent the construct. Typically, multiple linear regression models can be used as the statistical descriptions, but any statistical model that preserves the nature of the category response scale can be used, e.g., two-limit Tobit analysis.

(4) Each of the higher-order decision constructs are treated as factors whose levels are various ratings categories from the rating scales used to define the constructs in Step 2. For example, one might select three ratings categories from each decision construct as levels and construct a fraction of a $3^{N}$ design, where $N$ is the total number of higher-order decision constructs. Individuals are asked to imagine that they had given the ratings implied by each construct combination, and to respond to the combinations of construct ratings on a different category rating scale or to choose among two or more descriptions of higher-order construct ratings. For example, individuals might be asked to choose which of two higher-order supermarket construct rating descriptions they would be most likely to choose for grocery shopping.

(5) The response data from Step 4 are statistically analyzed using multiple linear regression or other methods if the response is on a category rating scale, or with a limited dependent variable model such as binary probit or logit if the response was which one of a pair is the 'best'. In this way a statistical model of the integration of the higher-order construct information is produced.

(6) The separate statistical models that define each higher-order construct can be concatenated with the overall model produced in Step 5 if one is willing to assume that each separate decision process has an error distribution whose expectation is zero and which is uncorrelated with any of the error distributions of the other decision processes.

Louviere \& Gaeth (1987), provide an example of this approach applied to an analysis of supermarket shopping behaviour. Four higherorder supermarket decision constructs were identified based on previous research : prices, selection, quality and convenience. Separate attributes were used to describe each of these constructs, and different experimental designs were developed to create combinations of the levels of attributes that defined each construct. The four higher-order decision constructs were treated as factors and two fractions of a $3^{4}$ factorial were used to produce 25 different combinations of 3 ratings category levels that spanned the range of the rating scale that the subjects used in each separate higher-order construct task. Subjects responded to the nine higher-order construct combinations on a $150 \mathrm{~mm}$ line-mark response scale. The two designs combined to allow one to estimate all main and two-way interaction effects of the higher-order constructs. The results of this study demonstrated that subjects used at least 17 of the 22 attributes varied in the experiments, and that the overall decision process was not additive. An application in the context of recreational choice behaviour is given in Louviere \& Timmermans (1990a).

The Hierarchical Information Integration approach was extended to choice rather than preference problems by Louviere \& Timmermans (1990b), in a study of residential preferences in the Roermond region of the Netherlands. In this study, attributes are grouped into those associated with the house, the surrounding residential environment, the location of the house vis-a-vis facilities and the transport system, and the subjects' social environment. Separate attributes are used to define each of these higher-order constructs.

An important unresolved question dealing with the Hierarchical Information Integration approach concerns how attributes are grouped into separate decision constructs. In particular, it is not clear whether different groupings of attributes will affect the results. For example, subjects in real shopping environments may not evaluate prices independently of some of the other attributes that describe the other constructs. On the other hand, the groupings employed in the Dutch residential choice study, because they are based on considerable previous empirical work, may be closer to reality. In any case, research is needed into the effects of different ways of grouping attributes on the results.

\section{Dealing with attributes that are correlated in real markets}

In order to achieve estimation efficiency, most decompositional decision experiments make use of orthogonal attribute arrays. Unfortunately, such arrays often produce infeasible or impossible choice alternatives. Although a well-known problem, most researchers ignore 
it or attempt to accommodate it by collapsing levels of two or more correlated attributes into one 'composite' attribute. Recently, Louviere (1985) has suggested a potential solution to this problem that applies to a limited, but important set of multiattribute problems in which all of the attributes of interest are quantitative.

The approach is based on difference-inutility functions, and requires individuals to make comparative or 'difference' judgments about two or more alternatives. The idea behind difference-in-utility models is to (a) develop an arbitrary 'base' alternative whose attributes have the correlation properties of interest; (b) construct an orthogonal difference design in which the elements of an orthogonal factorial array are differences between the levels of the 'base' attributes and the attribute levels of the non-base alternatives; (c) implement the task as a comparative judgment task or a choice task.

Thus, the differences in the levels of attribute vectors are designed to be orthogonal, but the vectors of absolute attribute levels can be correlated in whatever way the experimenter desires. The orthogonality of the difference vectors provides a basis for efficient estimation of difference-in-utility specifications. If discrete choice or allocation tasks are used to implement the experiments, one can analyze the response data with the same approaches to parameter estimation previously discussed for MNL choice models. In the case of comparative category rating judgments, one can analyze the data by means of OLS regression or related procedures such as two-limit Tobit analysis.

\section{Dealing with competitive environments}

Most applications of decompositional multiattribute decision methods have concentrated on generic attribute effects common to all choice alternatives. It is important in many planning and commercial contexts (not to mention of academic interest) to be able to anticipate the consequences of the introduction of a new alternative into environments in which existing and proposed alternatives are engaged in building a market and competing for shares of that market. Some of the developments already reported can be applied to such problems with appropriate modifications.

In this approach one must decide on the set of specific, named existing competitors that will be researched, as well as the new, named competitor(s) of interest. One must also decide on the possible competitive actions and reactions that are likely to be taken by the new and existing competitors. These actions and reactions are treated as experimental factors, and orthogonal designs are used to develop combinations of changes (the levels of the factors). As previously discussed, sets of choice sets can be constructed in several ways. (a) Each action or reaction of each competitor can be treated as a factor with differing numbers of levels, and an orthogonal main effects or other design can be used to construct sets of choice sets. (b) Each action or reaction within a particular competitor is treated as a factor, and a separate orthogonal design is constructed to vary these actions and reactions for each competitor. The treatment combinations from the separate designs for each competitor are randomly assigned to choice sets without replacement (or with replacement if the designs have differing numbers of treatments as discussed previously). (c) Balanced incomplete block or other designs are used to assign the treatments constructed by method $b$ to choice sets.

Samples of respondents are shown all or subsets of the choice sets and asked to indicate which alternative in each set would be the one that they would be most likely to choose most of the time. Alternatively, as previously discussed, subjects could be asked to allocate resources among the competing alternatives. These data can be analyzed by means of the various parameter estimation methods discussed in the article. Louviere (1984b) applied this approach to the study of marketing strategies for fast food restaurants. An application to a geographical/planning problem can be found in Timmermans et al. (1990), who used a similar approach to predict consumer choice of shopping centre following the introduction of a new centre in the Netherlands. Consumer behaviour in the Netherlands can be viewed as a choice among a hierarchy of centre types (local, regional and higher-level). Consequently, the local planning authorities of a small village wished to assess the effects of a new centre - and the types of shops that might be contained therein (currently subject to debate) introduced into a nearby town, as well as the possible effects on retail turnover of some planning measures that might be implemented by the major municipalities of the region.

The possible new shopping configurations 
can be described in terms of several attributes, and an experimental design can be used to vary some. The possible new regulations concern the two largest shopping centres in the region and include regulation of parking, construction of new intown hypermarkets, and location of discount stores. Each regulation may be implemented or not; hence, a $2^{3}$ factorial design describes all the possibilities. Finally, three different reaction strategies were considered which the local shopping centre could implement or not.

To study this problem, separate orthogonal arrays consisting of eight treatments each were used to vary various strategies and regulations that could be implemented or not. The eight treatments were randomly assigned to each of four specific shopping centres of interest without replacement to create eight choice sets. Respondents were asked to allocate their shopping activities to the four shopping centres, given the possible future developments. Weighted least-squares regression analysis was used to estimate the parameters of an MNL choice model that can be used to forecast future choices among the centres as a function of the changes in strategies and regulations.

\section{Discussion and conclusions}

This article discussed some recent advances in decompositional multiattribute decision modeling. The discussion indicated that a number of approaches have recently been de- veloped to wholly or partially solve a variety of previously unresolved problems and limitations associated with these models. As a result of these developments, experimentally based decompositional decision models represent an attractive alternative to econometric models for studying individual and group judgment and choice processes. Furthermore, decompositional models and methods offer a rich array of possibilities that can be used to approach a variety of spatial choice problems in geography and related fields. This contrasts starkly with the relatively limited array of applications for econometric discrete choice models based on statistically uncontrolled, observational data and relatively strong behavioural assumptions.

Consequently, the number of different types of choice problems that can be studied using conjoint choice simulators or controlled choice experiments has been expanded considerably. However, these advances also increase the complexity of experimental design construction for researchers and, in some cases, make tasks more complicated for subjects. Research into the reliability of choice data under changes in various experimental parameters, such as numbers of attributes, numbers of choice sets, and the like is therefore needed. We hope that the present article stimulates research into these important issues and problems of individual spatial choice behaviour.

\section{References:}

ANDERSON, N. H. (1981), Foundations of Information Integration Theory. New York: Academic Press.

ANDERSON, N. H. (1982), Methods of Information Integration Theory. New York: Academic Press.

BATES, J. J. (1988), Stated Preference Techniques and the Analysis of Consumer Choice. In: N. WRIGLEY, ed., Store Choice, Store Location \& Market Analysis, pp. 203-224. London: Routledge.

BR̃Adiey, M. A. \& P. H. L. Bovy (1984), A Stated Preference Analysis of Bicycle Route Choice. Paper presented at the Twelfth Annual Meeting of the PTRC, Warwich, Sussex.

Curry, D. J., J. J. Louviere, D. Rausch \& G. WoodWORTH (1983), Recreation Destination Choice. Final Report 35, Institute of Urban and Regional Research, University of Iowa.

Dinwoodie, J. (1989), A Stated Preference Approach to Forecasting Suburban Rail Demand in Eastern Plymouth. Paper presented at the Annual Meeting of the PTRC, Brighton, UK.

GreEN, P. E., S. M. Goldberg \& M. Montemayor (1981), A Hybrid Utility Estimation Model for Conjoint Analysis. Journal of Marketing 45, pp. 33-41.

GreEN, P. E. \& V. SRINIVASAN (1978), Conjoint Analysis in Consumer Research : Issues and Outlook. Journal of Consumer Research 5, pp. 103-123.

HAMmond, K. R., J. RoHRBAUGH, J. Mumpower \& J. ADELMAN (1977), Social Judgment Theory: Applications in Policy Formulation. In: S. Schwartz \& M. F. KaPlan, eds., Human Judgment and Decision Processes: Applications and Problem Setting, pp. 272-312. New York: Academic Press.

KRANTZ, D. H. (1964), Conjoint Measurement: The LuceTukey Axiomatization and Some Extensions. Journal of Mathematical Psychology 1, pp. 248-277.

KRANTZ, D. H. \& A. TVERSKY (1971), ConjointMeasurement Analysis of Composition Rules in Psychology. Psychological Review 78, pp. 151-169.

LIEBER, S. R. (1978), Place Utility and Migration. Geografiska Annaler B 60, pp. 16-27.

LIEBER, S. R. (1979), An Experimental Approach for the Migration Decision Process. Tijdschrift voor Economische en Sociale Geografie 70, pp. 75-85.

LIEBER, S. R. \& D. R. FESENMAIER (1984), Modeling Recreation Choice: A Case Study of Management Alternatives in Chicago. Regional Studies 18, pp. 31-43. LOUVIERE, J. J. (1979), Modeling Individual Residential Preferences : A Totally Disaggregate Approach. Trans- 
portation Research A 13, pp. 374-384.

LoUviere; J. J. (1984a), Hierarchical Information Integration: A New Method for the Design and Analysis of Complex Multiattribute Judgment Problems. In: T. C. KrnNeAR, ed., Advances in Consumer Research Vol. $X I$, pp. 148-155. Provo: Association for Consumer Research.

Louviere, J. J. (1984b), Using Discrete Choice Experiments and Multinomial Logit Choice Models to Forecast Trial in a Competitive Retail Environment: A Fast Food Restaurant Illustration. Journal of Retailing 60, pp. 81-107.

Louviere, J. J. (1985), Conjoint Judgment and Choice Models that Allow Correlated Attributes without Sacrificing Orthogonal Parameter Estimation. Unpublished manuscript.

Louviere, J. J. (1988a), An Experimental Design Approach to the Development of Conjoint Based Choice Simulation Systems with an Application to Forecasting Future Retirement Migration Destination Choices. In: R. G. Golledge \& H. J. P. Thmmermans, eds., Behavioural Modelling in Geography and Planning, pp. 325-355. Beckenham, Kent: Croom Helm.

LoUVIERE, J. J. (1988b), Analyzing Decision Making: Metric Conjoint Analysis. London: Sage.

LOUVIERE, J. J. \& G. GAETH (1987), Decomposing the Determinants of Retail Facility Choice Using the Method of Hierarchical Information Integration: A Supermarket Illustration. Journal of Retailing 63, pp. 25-48.

Louviere, J. J. \& D. A. Hensher (1983), Design and Analysis of Simulated Choice or Allocation Experiments in Travel Choice Modelling. Transportation Research Record 890, pp. 11-17.

LoUviERE, J. J. \& K. Norman (1977), Applications of Information Processing Theory to the Analysis of Urban Travel Demand. Environment and Behavior 9, pp. 91-106.

Louviere, J. J. \& H. J. P. TIMMERMans (1990a), Using Hierarchical Information Integration to Model Consumer Responses to Possible Planning Actions : Recreation Destination Illustration. Forthcoming in Environment and Planning $A$.

Louviere, J. J. \& H. J. P. TMMmermans (1990b), Hierarchical Information Integration Applied to Residential Choice Processes. Forthcoming in Geographical Analysis.

Louviere, J. J. \& G. G. Woodworth (1983), Design and Analysis of Simulated Consumer Choice or Allocation Experiments : An Approach Based on Aggregate Data. Journal of Marketing Research 20, pp. 350-367.

LOUVIERE, J. J., G. G. WoODWORTH \& D. A. ANDERSON (1981), Predicting Consumer Choice of Destination and Ticket for International Travel from Australia. Paper presented to the South Pacific Meetings of the Regional Science Association, Surfers' Paradise, Queensland, Australia, August.

LUCE, R. D. (1959), Individual Choice Behavior. New York: John Wiley.

LuCE, R. D. (1977), The Choice Axiom After Twenty Years. Journal of Mathematical Psychology 15, pp. 215-233.

LUCE, R. D. \& J. W. TUKEY (1964), Simultaneous Conjoint Measurement: A New Type of Fundamental Measurement. Journal of Mathematical Psychology 1, pp. 1-27.
Moore, L. (1988), Stated Preference Analysis and New Store Location. In: N. WRIGLEY, ed., Store Choice, Store Location \& Market Analysis, pp. 203-224. London: Routledge.

NAKANISHI, M. \& L. G. CoOPER (1974), Parameter Estimation for a Multiplicative Competitive Interaction Model-Least Squares Approach. Journal of Marketing Research 11, pp. 303-311.

NoRMAN, K. L. \& J. J. LoUviERE (1974), Integration of Attributes in Bus Transportation: Two Modelling Approaches. Journal of Applied Psychology 59, pp. 753-758.

PhIPPS, A. \& W. A. V. ClaRK (1988), Interactive Recovery and Validation of Household's Residential Utility Functions. In: R. G. GolledGe \&H. J. P. TMMmermans, eds., Behavioural Modelling in Geography and Planning, pp. 245-271. Beckenham, Kent: Croom Helm.

Prosperi, D. C. \& H. J. SchUler (1976), An Alternate Method to Identify Rules of Spatial Choice. Geographical Perspectives 38, pp. 33-38.

SchUlER, H. J. (1979), A Disaggregate Store-Choice Model of Spatial Decision-Making. The Professional Geographer 31, pp. 146-156.

Schuler, H. J. \& D. H. Prosperi (1978), A Conjoint Measurement Model of Consumer Spatial Behavior. Regional Science Perspectives 8, pp. 122-134.

THEII, H. (1969), A Multinomial Extension of the Linear Logit Model. International Economic Review 10 , pp. 251-259.

TIMMERMans, H. J. P. (1980), Unidimensional Conjoint Measurement Models and Consumer Decision-Making Processes. Area 10, pp. 391-400.

Timmermans, H. J. P. (1982), Consumer Choice of Shopping Centre: An Information Integration Approach. Regional Studies 16, pp. 171-182.

TIMMERMans, H. J. P. (1984), Decompositional Multiattribute Preference Models in Spatial Choice Analysis : A Review of Some Recent Developments. Progress in Human Geography 8, pp. 189-221.

Timmermans, H. J. P. (1986), Locational Choice Behaviour of Entrepreneurs: An Experimental Analysis. Urban Studies 23, pp. 231-240.

Timmermans, H. J. P., A. W. J. Borgers \& P. J. H. J. VAN DER WAERDEN (1990), Modelling the Effect of Planned Retail Change. Forthcoming.

ThMmermans, H. J. P. \& R. E. C. M. 'van DER HeIJden (1984), The Predictive Ability of Alternative Decision Rules in Decompositional Multiattribute Preference Models. Sistemi Urbani 5, pp. 89-101.

ThMmermans, H. J. P., R. E. C. M. van der HeIJden \& H. Westerveld (1984), Decision-Making Between Multiattribute Choice Alternatives: A Model of Spatial Shopping Behaviour Using Conjoint Measurements. Environment and Planning $A$ 16, pp. 377-387.

VeldHUISEN, K. J. \& H. J. P. TMMMERMans (1984), Specification of Individual Residential Utility Functions: A Comparative Analysis of Three Measurement Procedures. Environment and Planning $A 16$,pp. 1573-1582.

WoodworTH, G. G. \& J. J. LouvIERE (1985), Simplified Estimation of the Multinomial Logit Choice Model Using Iteratively Reweighted Least Squares. Paper Presented to the Annual ORSA/TIMS Marketing Science Meetings, Nashville, March. 